\title{
Alternative Methods for Managing Gastrointestinal Parasites and Eimeria Spp. in Small Ruminants
}

\author{
BR Min*, N Gurung and F Abrahamsen \\ Department of Agricultural and Environmental Sciences, Tuskegee University, USA
}

Submission: March 26, 2017; Published: May 23, 2017

"Corresponding author: BR Min, Department of Agricultural and Environmental Sciences, Tuskegee University, Tuskegee, AL 36088, Tel: 334-524-7670; Email: minb@mytu.tuskegee.edu

\section{Who Cares and Why?}

Infection with gastrointestinal nematodes (GIN) and coccidia (Eimeria spp.) remains one of the primary constraints to sustainable production of small ruminants world-wide, and with resistance to synthetic anthelmintics now reaching epidemic proportions in sheep and goat GIN, alternative (non-synthetic) control strategies are being explored. Infected animals have lower growth rates, reduced reproductive performance, and have higher rates of illness and death. In the past, sheep and goat producers relied heavily on anti-parasitic drugs. Unfortunately, GI parasites have become increasingly resistant to many of the ruminant anthelmintics. Alternative methods of GI parasite control for animals raised primarily on forages are vital for the sustainability and profitability of sheep and goat farms in the southern United States. Consequently, alternative, sustainable, and affordable methods of parasitic control are required. There is also a need to examine plant-based alternatives to control coccidios is in livestock because there are no FDA approved drugs to treat coccidiosis in small ruminants.

\section{What Has the Project Done so Far?}

Research has shown that legumes such as Sericea lespedeza (Lespedeza cuneata) contain condensed tannin (CT) with antiparasitic properties. The anti-parasitic properties of CT have been demonstrated to reduce GI parasitic infection in goats in Oklahoma and Georgia and in sheep in Louisiana and Arkansas. In a series of studies with goats and sheep of differing breeds, life stages (young, mature), and geographic regions of the southern and eastern U.S., including sericea lespedeza in the diet as fresh (grazed) or dried (hay, leaf meal, pellets) material has resulted in a reduction of gastrointestinal parasites eggs and coccidial oocysts in feces (up to 97 percent), lower numbers of adult parasites in the animals' stomach and intestines (up to 70 percent), and reduced development of gastrointestinal parasites eggs to infective larvae in simulated pasture conditions [1-3]. Researchers at Tuskegee University found potential benefits of pine bark (PB) supplementation on antiparasitic effects and improved feed efficiency. Pine bark is one of the abundant forest byproducts in the southern United States and contains 11-to-13 percent CT on a dry matter basis. By raising sheep and goats primarily on forage, farmers can reduce feed costs. Research demonstrates that goats fed on a PB diet have up to 30 percent fewer worms in a total ration, as well as lower instances of fecal egg count and fecal coccidian oocyst count. Feeding a pine bark diet reduced both male ( 64 percent) and female (59 percent) worm counts compared with the control (without PB) diet. In addition, mean dry matter intake, feed efficiency, average daily gain, and cold carcass weight were also greater for goats fed the pine bark diets. On-farm research with local farmers in Alabama also has shown that goats on a pine bark diet had 74 percent lower fecal egg counts and 5 percent better animal weight gain compared to control diets during three-month trials. Ground pine bark as a feed ingredient has the potential to improve animal performance while decreasing internal parasites and coccidian infection. On-going our study indicated that using pine bark in combination with sericea seems to be even more effective with artificially infected drug-resistant $H$. contortus. The extract from the bark of the pine tree (Pinusradiata), which is rich in condensed tannins, was reported to inhibit the life cycle of Coccidia as evidenced by decreased sporulation of the oocysts of E. tenella, E. maxima, and E. acervulina [4]. Thus, developing plantbased alternatives such as pine bark and other natural resources for GI parasites control would be expected to have a greater impact on the goat and sheep industries. This will allow development of Best Management Practices to prevent or treat coccidiosis and GI parasites in ruminant livestock [5-6].

Ultimately, by raising sheep and goats primarily on forage, farmers can reduce feed costs.

\section{Impact Statement}

Goats fed on a PB diet have up to 30 percent fewer worms in a total ration, as well as lower instances of fecal egg count and fecal coccidian oocyst count. 
Goats on a pine bark diet had 74 percent lower fecal egg counts and 5 percent better animal weight gain compared to control diets during three-month trials. Ground pine bark as a feed ingredient has the potential to improve animal performance while decreasing internal parasites and coccidian infection. Thus, developing plantbased alternatives such as pine bark and other natural resources for GI parasites control would be expected to have a greater impact on the goat and sheep industries. Development of Best Management Practices to prevent or treat coccidiosis and GI parasites in ruminant livestock. Raising sheep and goats primarily on forage can reduce farmers feed costs.

\section{Conclusion}

This research has enabled goat production to be a more sustainable and low-cost enterprise by mitigating internal parasites and coccidian infections of grazing animals, thus enhancing overall meat production, protecting animal and human health, increasing producer profits, and providing a stable and safe food supply.

\section{What Research is Needed?}

More research is needed to: study the direct mechanisms of tannins and parasite interactions; look for ways of validating the anti-parasitic plants of sheep and goats production systems; and to continue testing the effectiveness of alternative natural dewormers for use in ruminants.

\section{References}

1. Burke JM, Miller JE, Mosjidis JA, Terrill TH (2012) Use of a mixed sericea lespedeza and grass pasture system for control of gastrointestinal nematodes in lambs and kids. Vet Parasitol 186(3-4): 328-336.

2. Burke JM, Miller JE, Mosjidis JA, Terrill TH (2012) Grazing sericea lespedeza for control of gastrointestinal nematodes in lambs. Vet Parasitol 186(3-4): 507-512.

3. Min BR, Pomroy W, Hart SP, Sahlu T (2004) The effect of short-term consumption of a forage containing condensed tannins on gastrointestinal nematode parasite control in grazing wether goats. Small Ruminant Research 51(3): 279-283.

4. Min BR, Hart SP, Tomita G, Loetz E, Sahlu T (2005) The effect of condensed tannins on gastrointestinal parasite control in Angora Does. Veterinary Parasitology 130: 105-113.

5. Molans AL, Liu Z, De S (2009) Effect of pine bark (Pinusradiata) extracts on sporulation of coccidian oocysts. Folia Parasitol 56(1): 1-5.

6. Terrill TH, Dykes GS, Shaik SA, Miller JE, Kouakou B, et al. (2009) Efficacy of sericea lespedeza hay as a natural dewormer in goats: dose titration study. Vet Parasitol 163(1-2): 52-56.

\section{Your next submission with Juniper Publishers} will reach you the below assets

- Quality Editorial service

- Swift Peer Review

- Reprints availability

- E-prints Service

- Manuscript Podcast for convenient understanding

- Global attainment for your research

- Manuscript accessibility in different formats

( Pdf, E-pub, Full Text, Audio)

- Unceasing customer service

Track the below URL for one-step submission https://juniperpublishers.com/online-submission.php 